\title{
Proximal gastric vagotomy versus long-term maintenance treatment with cimetidine for chronic duodenal ulcer: a prospective randomised trial
}

\author{
M W L GEAR
}

\begin{abstract}
Forty-four patients with chronic duodenal ulceration were allocated randomly to either long-term maintenance treatment with cimetidine or proximal gastric vagotomy. All were followed up both clinically and endoscopically for periods of one to four years. The rate of recurrence of ulcer during and after medical treatment was $54 \%$ while after surgery it was $10 \%$. One patient developed severe allergic hepatitis while. receiving maintenance treatment with cimetidine, and two others had to stop treatment because of possible drug reactions.

Patients whose ulceration recurs while they are receiving treatment with cimetidine should be offered the possibility of operation.
\end{abstract}

\section{Introduction}

Early clinical experience with cimetidine showed the efficacy and safety of the drug in the treatment of duodenal ulcer. ${ }^{1}$ Subsequent trials of maintenance treatment showed that lowdose cimetidine was effective in preventing relapse of the ulcer. ${ }^{2}$ The established indications for surgical treatment came under question: one surgeon went so far as to impose a moratorium on surgery for uncomplicated ulcer, believing that most patients responded sufficiently well to cimetidine. ${ }^{3}$ Others proposed schemes for selecting patients for surgery on the basis of differing responses to cimetidine in the short or longer term. ${ }^{45}$

When cimetidine was introduced in 1976 proximal gastric vagotomy was becoming firmly established, having a lower mortality and fewer side effects than other operations for duodenal ulcer. ${ }^{6}$ ? Thus in 1977 there was a dilemma for the doctor when advising his patient with an uncomplicated chronic duodenal ulcer. On the one hand, cimetidine offered rapid and simple relief of symptoms but with uncertainty about long-term efficacy and safety. On the other hand, surgery was well proved, safe, and with a low morbidity but again with uncertainty about long-term efficacy and safety.

In an attempt to resolve some of these problems a prospective randomised trial was set up in 1977.

\section{Patients and methods}

The patients studied had duodenal ulcer confirmed by endoscopy; all fulfilled indications for surgery established before the advent of cimetidine. At presentation in the clinic they were asked whether they would accept either surgery or long-term medical treatment with cimetidine. Those who accepted were randomly allocated to surgery by proximal gastric (highly selective) vagotomy or to medical treatment consisting of three months' full dosage with cimetidine $200 \mathrm{mg}$ three times daily and $400 \mathrm{mg}$ at night followed by indefinite maintenance with $400 \mathrm{mg}$ nightly.

Departments of Surgery and Endoscopy, Gloucestershire Royal Hospital, Gloucester GL1 3NN

$M$ W L GEAR, DM, MCH, consultant surgeon
Patients were seen every three months for the first year and sixmonthly thereafter in the outpatient department. The importance of regular medication was emphasised at each visit. Routine haematological and biochemical investigations were performed. Endoscopy was performed at three months and thereafter yearly or when symptoms arose.

In the four years from early 1977 to early 1981, 44 patients were admitted to the trial, including some who had received previous treatment with cimetidine, which has little effect on the long-term course of the disease. Patients who developed recurrent ulcers while receiving maintenance treatment were offered either a further course of full-dose cimetidine or surgery.

\section{Results}

The age, ratio of men to women, duration of symptoms, and smoking habits of the patients in the two treatment groups were comparable (table).

Randomised trial of medical versus surgical treatment for chronic duodenal ulcer

\begin{tabular}{lccccc}
\hline & No of & $\begin{array}{c}\text { Average } \\
\text { patients } \\
\text { age } \\
\text { (years) }\end{array}$ & $\begin{array}{c}\text { Duration of } \\
\text { history } \\
\text { (and range) } \\
\text { (years) }\end{array}$ & M:F & $\begin{array}{c}\text { Smokers: } \\
\text { non- } \\
\text { smokers }\end{array}$ \\
\hline Cimetidine maintenance & 24 & $50 \cdot 2$ & $\begin{array}{c}10 \cdot 8 \\
(2-40)\end{array}$ & $20: 4$ & $18: 6$ \\
Proximal gastric vagotomy & 20 & $48 \cdot 5$ & $\begin{array}{c}8 \cdot 4 \\
(0 \cdot 5-20)\end{array}$ & $18: 2$ & $16: 4$ \\
\hline
\end{tabular}

PATIENTS TREATED WITH CIMETIDINE

Twenty-four patients received maintenance treatment, nine for over a year, nine for over two years, and six for over three years. Eleven patients $(46 \%)$ remained symptom free and with healed ulcers while $13(54 \%)$ developed a recurrence or had continuing symptoms (seven $(29 \%)$ while still receiving treatment and six $(26 \%)$ after treatment had been stopped). Nine of the 13 patients had troublesome and two mild symptoms; two patients were asymptomatic.

Recurrences during treatment-Two patients developed recurrences early (at three and six months) despite receiving full dosage: one requested surgery and the other persisted with treatment for another course but the ulcer remained unhealed. The remainder of the recurrences occurred after periods of healing varying from one to three and a half years. Thus initial healing and successful early maintenance do not necessarily predict continuing remission. Three patients were rather irregular in their dosage : two developed recurrent ulcers; in the other the ulcer remained healed but severe symptoms continued.

Recurrences and problems after treatment-Six patients developed recurrent ulcers within a few months of stopping treatment. Four of these patients were withdrawn from the trial because of complications or recurrent symptoms and two because they had completed over three years of treatment. Most of the patients with recurrent ulcers were treated by operation; the ulcers remained healed at follow-up. Patient compliance was not studied in detail but seemed good at followup visits in all except two patients. One further patient refused further treatment after two years, despite being symptom free and having a healed ulcer. He eventually underwent proximal gastric vagotomy for a return of symptoms even though ulceration had not recurred. One unrelated death from myocardial infarction occurred in a patient who had been receiving treatment for nearly two years. The ulcer had 
been seen to be healed four months before death. Another patient became pregnant after three years of successful treatment; cimetidine was stopped during the pregnancy and subsequently, and she remained well. The baby was normal.

\section{PATIENTS TREATED WITH VAGOTOMY}

The results of proximal gastric vagotomy in the 20 patients were good, and 17 patients were followed up for over two years. Ulcers recurred in two patients two years after operation: one recurred during a prolonged bout of influenza, responded symptomatically to simple alkali treatment, and was seen to be healed at follow-up endoscopy; the other healed on treatment with cimetidine. In both cases the vagotomy appeared to be complete on acid testing. Two patients had mild symptoms, mostly heartburn, easily controlled by occasional simple medication. The 16 other patients had no symptoms at all. One died from carcinoma of the pancreas over two years after successful vagotomy. The results of surgical treatment were classified into Visick grades as follows: 16 patients were grade I; two were grade II; and two (with recurrent ulcers, one of which was transient) were grade IV.

\section{COMPLICATIONS}

Complications developed in eight patients. In the patients who received cimetidine the complications were death from myocardial infarction after one and three-quarter years of treatment (one case); persistently raised serum alanine aminotransferase activity (one); severe allergic hepatitis (one; this was the most severe complication and occurred after two years of successful treatment); and severe keratoconjunctivitis (one). In the patients who underwent vagotomy complications were death from carcinoma of the pancreas two and a half years after operation (one); severe wound infection (one); and incisional hernia (two).

\section{Discussion}

Since this trial was planned reports from several centres ${ }^{13} 11$ with larger numbers of patients have given results in line with the series presented here. Recurrence occurs both during and after maintenance treatment, even when this is continued for years. There is thus little benefit in continuous maintenance treatment in many patients. Other patients, however, seem to fare extremely well with long-term cimetidine, the problem at present being the inability to select these patients.

The results in the patients who underwent vagotomy were also similar to those reported in other large series, with an incidence of recurrence of between $5 \%$ and $10 \%$. Eighteen of the 20 patients were graded as Visick I or II, having either no symptoms at all or minor symptoms not requiring medication.
A frequent comment at follow-up visits of patients treated by vagotomy after years of medical treatment is: "I wish I had had the operation years ago."

The unusual feature of this trial was the randomisation of suitable patients to either medical or surgical treatment so that the two groups were strictly comparable. Previously comparisons between large series treated medically and surgically were necessarily difficult as different criteria was entailed in the selection of patients according to the type of treatment.

The results of this trial show that cimetidine has a valuable place in the initial treatment of patients with duodenal ulcer. Surgery may thus be avoided in those whose ulcers heal rapidly and stay healed. Recurrent ulcers may also be treated medically, but after one or two years it is reasonable to discuss vagotomy as an alternative with proved long-term benefit.

I am grateful to Professor David Johnstone of Leeds for the original suggestion for the trial. I thank Sister Downie and the staff of the endoscopy department for their support and Mrs J Askew, research assistant, for administrative and secretarial help. I am grateful to Smith, Kline and French Ltd for providing the cimetidine and secretarial support.

\section{References}

${ }^{1}$ Bardhan KD. Cimetidine in duodenal ulceration. In: Wastell C, Hance $\mathrm{P}$, eds. Cimetidine the Westminster symposium. Edinburgh: Churchill Livingstone, 1978:31-56.

${ }^{2}$ Gudman-Hoyer E, Jensen KB, Krag E, et al. Prophylactic effect of cimetidine in duodenal ulcer disease. Br Med f 1978; i:1095-7.

${ }^{3}$ Kirk RM. One man's view: duodenal ulcer-cimetidine or surgery ? Surgery Today 1980;1:41-2.

4 Venables CW, Stephen JG, Blair EL, et al. Cimetidine in the treatment of duodenal ulceration and the relationship of this therapy to surgical management. In: Wastell $\mathrm{C}$, Hance $\mathrm{P}$, eds. Cimetidine the Westminster symposium. Edinburgh: Churchill Livingstone, 1978:13-27.

${ }^{5}$ Kennedy TL. A critical appraisal of surgical treatment. In: Truelove SC, Willoughby CP, eds. Topics in gastro-enterology 7. Oxford: Blackwell Scientific Publications, 1978:131-7.

${ }^{6}$ Johnston D. Operative mortality and postoperative morbidity of highly selective vagotomy. $\mathrm{Br}$ Med $\mathcal{F}$ 1975;iv:545-7.

${ }^{7}$ Kennedy TL, Johnston GW, Macrae KD, Spencer EPA. Proximal gastric vagotomy: interim results of a randomized controlled trial. $\mathrm{Br} \mathrm{Med} \mathcal{J}$ 1975 ;ii:301-3.

${ }^{8}$ Small WP, Cay EL, Dugard P, et al. Peptic ulcer surgery: selection for operation by 'earning'. Gut 1969;10:996-1003.

${ }^{9}$ Bonnevie O. Survival in peptic ulcer. Gastroenterology 1978;75:1055-60.

10 Bardhan KD, Cole DS, Hawkins BW, Franks CR. Does treatment with cimetidine extended beyond initial healing of duodenal ulcer reduce the subsequent relapse rate? $\mathrm{Br}$ Med $\mathcal{F} 1982 ; \mathbf{2 8 4}: 621-3$.

11 Fitzpatrick WJE, Blackwood WS, Northfield TC. Bedtime cimetidine maintenance treatment: optimum dose and effect on subsequent natural history of duodenal ulcer. Gut $1982 ; 23: 239-42$.

12 Bardhan KD. Intermittent treatment of duodenal ulcer with cimetidine. Br Med $\mathcal{F} 1980 ; \mathbf{2 8 1}: 20-2$.

(Accepted 20 October 1982)
The common SELF-HEAL which is called also Prunel, Carpenter's Herb, Hook-heal, and Sickle-wort, is a small, low, creeping herb, having many small, roundish pointed leaves, like leaves of wild mints, of a dark green colour, without dents on the edges; from among which rise square hairy stalks, scarce a foot high, which spread sometimes into branches with small leaves set thereon, up to the top, where stand brown spiked heads of small brownish leaves like scales and flowers set together, almost like the heads of Cassidony, which flowers are gaping, and of a blueish purple, or more pale blue, in some places sweet, but not so in others. The root consists of many fibres downward, and spreading strings also whereby it increases. The small stalks, with the leaves creeping on the ground, shoot forth fibres taking hold on the ground, whereby it is made a great tuft in a short time. It is found in woods and fields every where. It flowers in May, and sometimes in April.

Here is another herb of Venus, Self-heal, whereby when you are hurt you may heal yourself: It is a special herb for inward and outward wounds. Take it inwardly in syrups for inward wounds: outwardly in unguents, and plaisters for outward. As Self-heal is like Bugle in form, so also in the qualities and virtues, serving for all the purposes whereto Bugle is applied to with good success, either inwardly or outwardly, for inward wounds or ulcers whatsoever within the body, for bruises or falls, and such like hurts. If it be accompanied with Bugle, Sanicle, and other the like wound herbs, it will be more effectual to wash or inject into ulcers in the parts outwardly. Where there is cause to repress the heat and sharpness of humours flowing to any sore, ulcers, inflammations, swellings, or the like, or to stay the fluxes of blood in any wound or part, this is used with some good success; as also to cleanse the foulness of sores, and cause them more speedily to be healed. It is an especial remedy for all green wounds, to solder the lips of them, and to keep the place from any further inconveniencies. The juice hereof used with oil of roses to anoint the temples and forehead, is very effectual to remove head ache, and the same mixed with honey of roses, cleanses and heals all ulcers, in the mouth, and throat, and those also in the secret parts. And the proverb of the Germans, French, and others, is verified in this, That he needs neither physician nor surgeon that hath Self-heal and Sanicle to help himself. (Nicholas Culpeper (1616-54) The Complete Herbal, 1850.) 